\title{
5
}

\section{Improving health outcomes}

There is strong international support for increasing government expenditures and donor funding to accelerate progress toward the Millennium Development Goals. Additional government health expenditures and donor funding, although they may improve health outcomes, in particular maternal mortality and mortality of children under five, are not likely to be sufficient to reach the Millennium Development Goals for health by 2015. Reaching these goals requires broad economic growth and investment, significant change in the way donor funding is provided, and more efficient health spending.

With so many countries not on track to meet the health-related Millennium Development Goals, the international community is now reaching a consensus that current health expenditure levels in developing countries are too low and that more resources are needed (see chapter 7). These discussions take for granted, however, that the additional expenditures and resources will bring about the desired health outcomes. The discussions also often ignore the additional actions required to improve the ability of countries to absorb and mobilize additional resources to reach the Millennium Development Goals.

This chapter contains new findings on the impact of government health expenditures and donor funding on health outcomes. These findings indicate that government health expenditures do indeed affect under-five mortality and maternal mortality, contrary to results reported in much of the literature to date. The results also show that donor funding has a direct impact on under-five mortality, but not on maternal mortality. Nonetheless, donor funding indirectly affects maternal mortality by increasing the impact of governmental health expenditures on this outcome.

These effects of donor funding on health outcomes can be explained in part by the volatility and fungibility of donor funding, as well as by the difficulties that governments face in reallocating resources in the short term after a donor has decreased or discontinued funding. This chapter reviews these effects and their implications for reaching the Millennium Development Goals for child mortality and maternal mortality across different regions. The chapter concludes by addressing the fundamental issues for improving countries' chances of reaching the Millennium Development 
Goals for health. These issues include stimulating economic growth and multisectoral investment, as well as changing the way donor funding is provided and government health expenditures are used, so that these critical resources produce better health outcomes. Three key lessons emerge from the discussion:

- Neither increased government health expenditures nor GDP growth alone are sufficient for reaching the health Millennium Development Goals. Although both expenditures and growth affect health outcomes, long-term investments in infrastructure, education, and water and sanitation are also needed. Furthermore, GDP growth is essential not only because it generates greater personal income, which directly boosts health outcomes, but also because it generates government revenues that can support a multisectoral approach to health investments.

- Recipient countries must improve their capacity to absorb and use additional health resources by strengthening policies and institutions for managing public expenditures. Resources, even if available, must be made accessible regularly and on time where health services are to be delivered; this effort requires efficient public expenditure management from central to local government and from local government to the service facility. It also implies appropriate accountability at all levels of government. (Such accountability is further reviewed in chapter 6.)

- Donors must carefully evaluate their role and desired impact in country-specific contexts to improve the consistency between donor and country objectives. Donor aid now has a limited direct impact on health outcomes, in part because of the fungibility, volatility, and asymmetry in budgeting (see chapter 4 ). ${ }^{1}$ To improve outcomes, donors must

$\diamond$ Exercise care in designing aid programs and evaluating the impact of their funds.

$\diamond$ Give serious consideration to supporting government budgets directly through general budget support. Donors should agree with governments on a program, rather than directly finance projects that may crowd out the government's own resources.

\& Commit to predictable financing over long maturities to provide budget support to existing government programs. This action is especially important given the recurrent nature of many health expenditures, which make them unsuitable for financing through short-term grants.

$\diamond$ Directly fund projects only in cases of major government failure, especially in public expenditure management.

^ Provide technical assistance as the first priority in cases of government failure to improve public expenditure management and government capacity. 


\section{Government health expenditures}

The theoretical link between increases in government health expenditures and improved health outcomes is complex for several reasons. First, an increase in government health expenditures may result in a decrease in private health expenditures-a household may divert its funds to other uses once the government increases its basic health expenditures. Second, incremental government expenditures may be employed ineffectively (for instance, expenditures allocated to high-tech equipment or advanced hospitals may have little effect on public health if morbidity indicators show the need for increased resources for primary care). Third, even if extra funds are applied appropriately, they may yield little benefit if complementary services, both inside and outside the health sector, are lacking (for example, roads or transportation services to hospitals and clinics and easy access to water and sanitation) (Wagstaff 2002a).

The empirical literature has not shed much light on the link between public spending and health outcomes. Early studies (as summarized by Musgrove in 1996) find no evidence that total spending on health has any impact on child mortality. Filmer and Pritchett (1999) find that government health expenditures account for less than one-seventh of one percent of the variation in under-five mortality across countries, although the result was not statistically significant. They conclude that 95 percent of the variation in under-five mortality can be explained by factors such as the country's per capita income, female educational attainment, and choice of religion. Finally, using a model similar to that of Filmer and Pritchett, Wagstaff and Claeson (2004) showed more recently that good policies and institutions (as measured by the World Bank's Country Policy and Institutional Assessment or CPIA Index) are important determinants of the impact of government health expenditures on outcomes. In particular, as the quality of policies and institutions improves (as the CPIA Index rises), the impact of government health expenditures on maternal mortality, underweight children under age five, and tuberculosis mortality also increases and is statistically significant. However, the impact of government expenditures on under-five mortality remains not significantly different from zero.

\section{New findings on the impact of government and donor funding}

As discussed above, a large percentage of donor assistance for health is managed directly by the donor outside the recipient government's budgeting system-it is off-budget. A model developed for this report ${ }^{2}$ attempts to capture both the direct and indirect impact of these off-budget resources on health outcomes. Donor funding levels and the volatility of donor funding are included in the model as explanatory variables. ${ }^{3}$ In addition, the critical relationship and interaction between donor funding and public health spending is also taken into account to 
capture the impact of the fungibility of aid with respect to domestically financed public spending. ${ }^{4}$

The impact of government health expenditure is of key interest. In contrast to other results presented in the literature, this study found that a 10 percent increase in government health expenditures has a larger net impact ${ }^{5}$ in reducing under-five mortality and maternal mortality than a 10 percent increase in education, roads, or sanitation. Government health expenditures also have as large an impact as income on under-five mortality but a smaller impact on maternal mortality. ${ }^{6}$ In addition, for a 10 percent increase in government health expenditures, the decrease in maternal mortality is typically 1 percentage point more than the decrease in under-five mortality. In Albania, for example, a 10 percent increase in government health expenditures (from the current observed value of 92 Int\$ per capita to 101.2 Int\$) implies a 4.1 percent reduction in under-five mortality and a 5.5 percent reduction in maternal mortality. ${ }^{7}$ In absolute terms, this would reduce under-five mortality from 26 per 1,000 to 24.8 per 1,000 and maternal mortality from 55 per 100,000 to 52 per 100,000.

Another important finding concerns the effect of donor funding on healthrelated outcomes. Donor funding can make an important dent in under-five mortality-but only when it is predictable and sustained. In contrast, neither the amount nor the volatility of donor funding has a direct impact on maternal mortality. ${ }^{8}$ Donor funding does have an indirect impact on maternal mortality, however, through its impact on government expenditures. This likely arises from the fungibility of donor funding. If the recipient country takes these external and largely off-budget funds into consideration in the allocation of its own domestic resources and spends more of its own money on, say, secondary care such as hospitals, which typically are not funded by donors, the increased and sustained expenditure on secondary care may increase the effect of government expenditures on maternal mortality. Table 5.1 shows the regression results for under-five mortality and maternal mortality. ${ }^{9}$

\section{Reaching the Millennium Development Goals for health}

Will the Millennium Development Goals, at least for under-five mortality and maternal mortality, be reached? What are the implications for policy development? Several conclusions can be drawn from this model and other work in the literature. $^{10}$

Continuing current levels of financing and growth and lack of coordination across sectors- "business as usual"-would mean that none of the developing regions of the world, according to the World Bank's regional classifications, will reach the Millennium Development Goal for under-five mortality (figure 5.1). Moreover, the slow progress from 1990 to 2000 implies that, to reach the under-five mortality goal in 2015 , the annual rate of decline in mortality would have to be larger than the average 4.2 percent needed originally (as represented by the target 
TABLE 5.1 Model regression results for under-five mortality and maternal mortality

\begin{tabular}{|c|c|c|}
\hline Variable & Under-five mortality & Maternal mortality \\
\hline \multirow[t]{2}{*}{ intercept } & $8.2591^{++}$ & $9.9084^{++}$ \\
\hline & $(0.08477)$ & (1.4544) \\
\hline \multirow[t]{2}{*}{$\ln E$} & 0.0651 & $0.3082^{++}$ \\
\hline & $(0.0427)$ & $(0.0863)$ \\
\hline \multirow[t]{2}{*}{$\ln R$} & $-0.0868^{++}$ & $-0.1019^{++}$ \\
\hline & $(0.0241)$ & $(0.0415)$ \\
\hline \multirow[t]{2}{*}{$\ln S$} & 0.0493 & 0.1708 \\
\hline & $(0.1115)$ & $(0.1533)$ \\
\hline \multirow[t]{2}{*}{ InVol } & $0.096^{++}$ & 0.0604 \\
\hline & $(0.029)$ & (0.0408) \\
\hline \multirow[t]{2}{*}{$\operatorname{lnGDP}$} & $-0.3689^{++}$ & $-0.5320^{+}$ \\
\hline & $(0.1348)$ & $(0.2477)$ \\
\hline \multirow[t]{2}{*}{$\operatorname{lnGh}$} & $-0.3708^{++}$ & $-0.4286^{+}$ \\
\hline & $(0.1082)$ & $(0.2026)$ \\
\hline \multirow[t]{2}{*}{$\operatorname{lnDF}$} & $-0.0429^{+}$ & -0.0348 \\
\hline & $(0.0233)$ & $(0.0367)$ \\
\hline \multirow[t]{2}{*}{$\operatorname{lnGh*DF}$} & -0.0122 & $-0.0340^{+}$ \\
\hline & $(0.01)$ & $(0.0175)$ \\
\hline $\mathrm{R}^{2}$ & 0.8216 & 0.7414 \\
\hline Adjusted $R^{2}$ & 0.8079 & 0.7215 \\
\hline
\end{tabular}

Source: World Bank staff estimates.

Note: Parameter standard errors are given in parenthesis. Estimates are based on the regression model presented in annex 5.1.

$\mathrm{E}=$ education, $\mathrm{R}$ = roads, $\mathrm{S}=$ sanitation, $\mathrm{Vol}$ = volatility of donor funding, GDP = gross domestic product per capita, $\mathrm{Gh}=$ government health expenditure, $\mathrm{DF}=$ donor funding.

${ }^{++} \mathrm{p}$-value $=0.01$ or less; ${ }^{+} \mathrm{p}$-value $=0.05$ or less

bar on the figure). ${ }^{11}$ For example, in East Asia and Pacific, under-five mortality would have to decline at a new rate of about 5 percent a year from 2001 to 2015 (black square on figure 5.1), almost double the current rate of 2.7 percent, as averaged over the period 1990-2000 and represented by the top shaded area. In the case of Sub-Saharan Africa, the rate of decline in under-five mortality has to accelerate from less than 0.5 percent a year between 1990 and 2000 to close to 8 percent a year between 2001 and 2015 to reach the Millennium Development Goal.

The outlook is more optimistic for maternal mortality (figure 5.2). Nonetheless, the business-as-usual trend will not be sufficient to reach the Millennium Development Goal, except in the Middle East and North Africa and East Asia and 
FIGURE 5.1 Progress toward reducing under-five mortality, by region

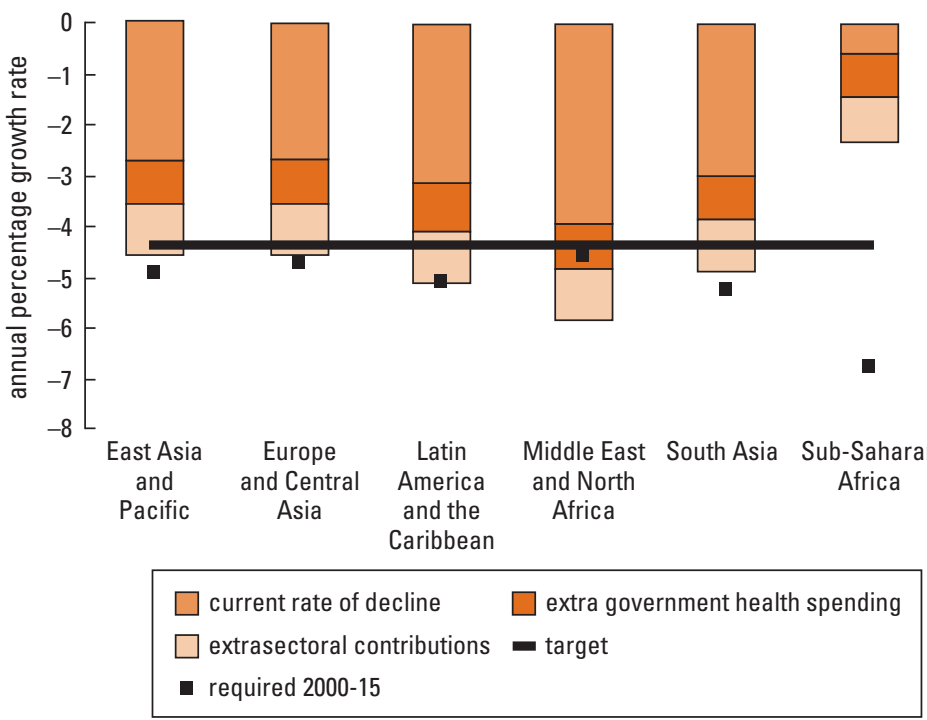

Source: World Bank staff estimates based on the model presented in annex 5.1.

Note: Extrasectoral contributions include contributions from the variables for income, education, roads, sanitation, and donor funding. Those contributions, as well as government health expenditure, are assumed to grow at 2.5 percent annually. Volatility of donor funding is assumed to be decreasing at 2.5 percent (by the end of 2015 donor funding will be one-third less volatile). Regional averages are population weighted.

Pacific regions. The annual rates of decline in maternal mortality will have to change in South Asia from about 3 percent in the 1990s to about 7 percent in 2000 to 2015 and in Europe and Central Asia from about 4 percent to 6 percent. The rate of decline in Sub-Saharan Africa and Latin America and the Caribbean would have to change from less than 2 percent a year to close to 8 percent. For Latin America and the Caribbean, this steep target may be partially due to the low baseline maternal mortality ratio in the region in 1990. The difficulty that the region is likely to have in reaching this target suggests that returns to delivery of appropriate services to reduce maternal mortality for the most marginalized women are diminishing. Efforts must be made to extend health services to remote areas and target the groups that are hardest to reach.

\section{A multisectoral effort needed}

Reaching the Millennium Development Goals requires a multisectoral effort plus growth in real GDP per capita. For most developing countries, anything short of this combined effort raises the likelihood that the goals will not be reached. For example, India has enjoyed an impressive real GDP per capita growth of 3.8 percent a year over the past four years. However, the model simulations show that 
FIGURE 5.2 Progress toward reducing maternal mortality, by region

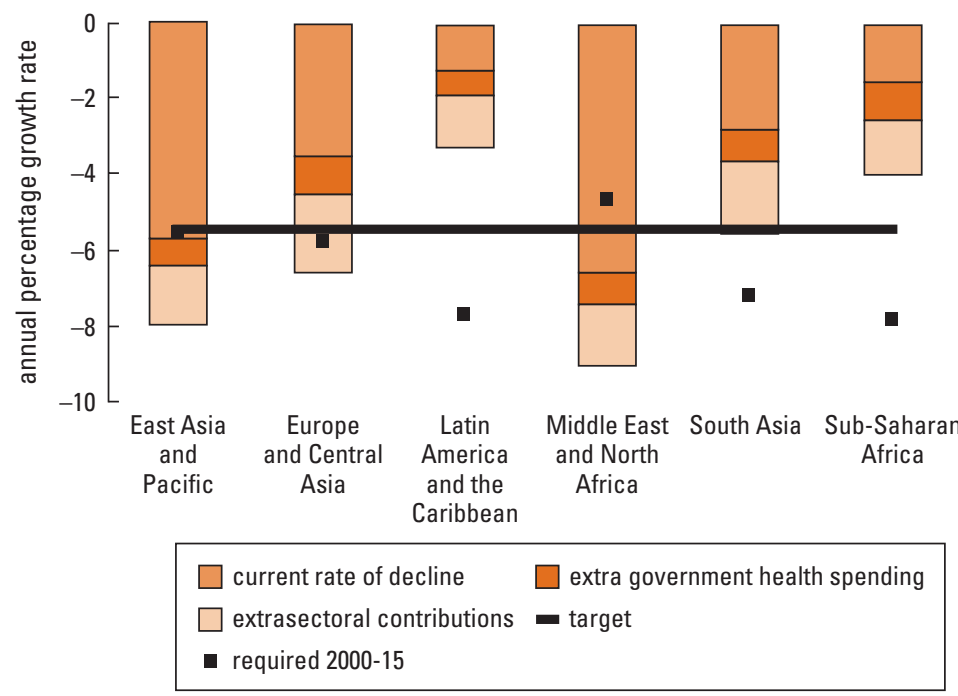

Source:World Bank staff estimates based on the model presented in annex 5.1.

Note: Extrasectoral contributions include contributions from the variables for income, education, roads, sanitation, and donor funding. Those contributions, as well as government health expenditure, are assumed to grow at 2.5 percent annually. Volatility of donor funding is assumed to be decreasing at 2.5 percent (by the end of 2015, donor funding will be one-third less volatile). Regional averages are population weighted.

even this impressive growth of income will fall short of the 15 percent increase in real GDP per capita needed over the period 2000 to 2015 if the Millennium Development Goals are to be reached through growth alone.

Similarly, resources devoted to health expenditures are insufficient by themselves to reach the goals. For instance, in Rwanda, per capita public expenditures would have to increase from $\$ 3.1$ a year in 2004 to more than $\$ 56$ in constant 2000 dollars by 2015 . With no growth, the country would be spending more on health than the government collects in total revenues. A multisectoral approach with investments in infrastructure, education, and health is needed. Growth must occur, not only because of the direct impact of income on outcomes, but also because the financing of the multisectoral approach requires such growth and the revenues that it generates.

The combination of increasing health expenditures and growth would most likely help low-income countries come closer to reaching the Millennium Development Goals related to maternal and child mortality, but for a few countries even this formula would not work (figure 5.3). Kenya, Rwanda, and Sudan, for example, would not reach the under-five mortality goal even with ambitious increases in real per capita growth rates of 5 percent a year (above an average of -1.1 percent, 3.3 percent, and 3.9 percent, respectively, over the past four years) 


\section{FIGURE 5.3 Under-five mortality targets and projected rates in Kenya, Rwanda, and Sudan}

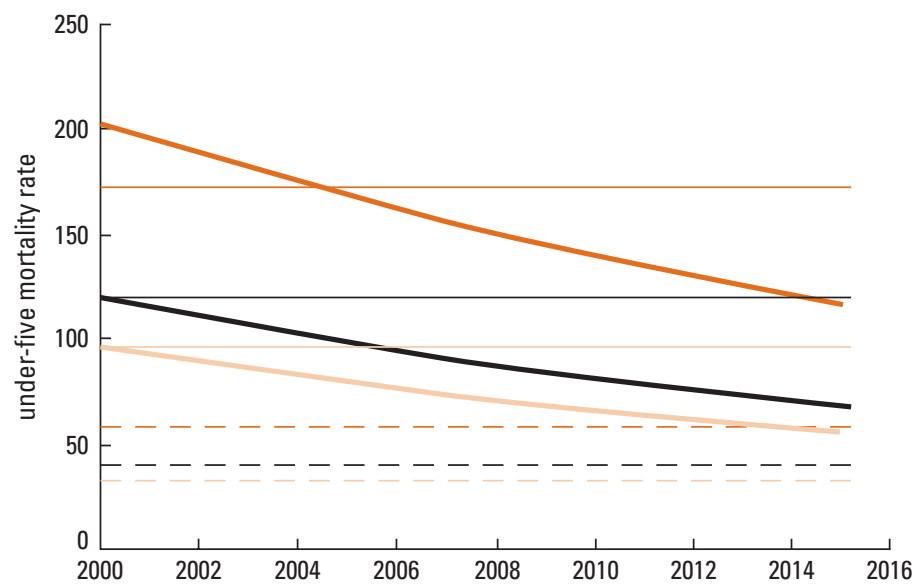

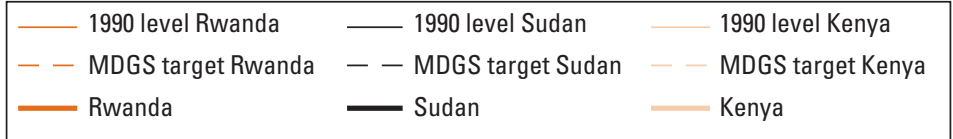

Source: World Bank staff estimates based on the model presented in annex 5.1.

Note: Projections for all three countries assume a positive 5 percent change per year in government health expenditures, education, infrastructure, water supply and sanitation, and donor funding. The solid line below the dotted line for Rwanda implies that under-five mortality in 1990 was below the 2000 estimate.

and increases of 5 percent a year in government health spending and the other explanatory variables of the model (education, roads, sanitation, and donor funding). According to the model, it would take very optimistic increases of 7 percent a year in real GDP per capita and government health expenditures, along with 5 percent annual increases in all the other variables, for these countries to reach the goal. To reach the Millennium Development Goal for maternal mortality by 2015 , these countries would require similarly optimistic growth in GDP per capita and public expenditures.

Countries that strive to meet the Millennium Development Goals on health through a multisector and growth approach will have to emphasize not only increasing investments in sectors that directly promote improved health outcomes, but also pursue efforts that influence growth rates. Recent World Bank work in this area suggests that those efforts involve trade, infrastructure, and the policies and institutions required for attracting investment, such as mechanisms for the protection of property rights and reliable judicial systems (Leipziger and others 2003; Paternostro, Rajaram, and Tiongson 2004; Herrera and Pan 2005). 


\section{Donors and predictable resources}

The model described in annex 5.1 shows that there is no direct impact of donor financing on maternal mortality ratios. Rather, the impact on maternal mortality occurs indirectly, by permitting an increase in the levels and sustainability of government health expenditures. Similarly, erratic donor financing does not have an impact on under-five mortality.

These results may be explained by the volatility and fungibility of donor funding, as well as by the difficulties governments have in reallocating resources from one priority to another. This implies that donors should not try to second guess recipient countries' priorities. Faster progress can be made by financing government programs, such as poverty reduction strategies, as the first priority. These programs must also be multisectoral, have appropriate growth strategies, and include efforts to improve policies and institutions. Donor funding must be predictable, stable, and sustained over a long period.

\section{Improving policies and institutions}

Wagstaff and Claeson (2004) have recently shown that policies and institutions are important for increases in spending to have a significant effect on health outcomes in achieving the Millennium Development Goals. The work shows that the impact of government health expenditures on outcomes is directly related to each country's policies and institutions, as reflected in the World Bank's measured assessment of country policies and institutions, the CPIA Index (see chapter 6). The authors conclude that increases in government health expenditures would not have an impact on any Millennium Development Goal outcome in countries with a CPIA below or at 3.25 (scale 1 through 5). Business as usual will not be sufficient in such countries. To reach the Millennium Development Goals, strong policy and institutional efforts are fundamental. These efforts include concentration on technical assistance to improve public expenditure management, administrative capacity, monitoring and evaluation, and mechanisms for ensuring accountability. 


\section{Annex 5.1 Government health expenditures, donor funding, and health outcomes: data and methods}

The discussion in chapter 5 is based, in part, on the estimates of the following reduced form equation:

$$
\begin{aligned}
\ln Y_{m}=\beta_{m 1} & +\beta_{m 2} \ln E+\beta_{m 3} \ln R+\beta_{m 4} \ln S+\beta_{m 5} \ln D F \\
& +\beta_{m 6} \ln I+\beta_{m 7} \ln G h+\beta_{m 8} D F \ln G h+\beta_{m 9} \ln V+v_{m}
\end{aligned}
$$

where $Y_{m}$ is either under-five mortality or maternal mortality. ${ }^{12}$ The functional form is based on the assumption that these health outcomes are a function of government health expenditures $(G h)$, national income $(I)$, education $(E)$, roads $(R)$ and sanitation $(S)$ as well as the level of off-budget donor funding $(D F)$ and volatility in donor funding $(V)$. The percentage change in under-five mortality (or maternal mortality) due to a percentage change in government health expenditures $(G h)$, can be estimated from equation (1) as $\beta_{\mathrm{m} 7}+\beta_{\mathrm{m} 8} \ln \mathrm{DF}$. It should be noted that a small change in government health expenditures may be associated with a direct change in under-five mortality (or maternal mortality) as well as a change in other Millennium Development Goal health indicators such as proportion of 1-year-old children immunized against measles and proportion of population in malaria-risk areas using effective malaria prevention. Furthermore, any change in these latter indicators (which are not included in the right-hand side of the equation) would also cause a change in, for instance, under-five mortality. Thus our elasticity measure gives the net percentage change in indicator $Y_{m}$ associated with a 1 percent change in $G$, holding $I, E, R, S, D F$, and $V$, but not the other Millennium Development Goals for Health indicators, constant. Finally, note that income and government health expenditures may both be correlated with the error term. We account for potential endogeneity of these variables through the use of instrumental variables within the generalized method of moments estimation techniques.

\section{Data sources and description}

Data on these variables were obtained from various sources and linked for 113 countries for the calender year 2000. The primary source was the World Bank's inhouse online database, SIMA, which is a collection of variables from various data sources including World Development Indicators, Millennium Indicators Database, World Health Report, and Human Development Report by the United Nations Children's Fund.

Under-five mortality is measured as the under-five mortality rate per 1,000 live births and maternal mortality is measured as the maternal mortality ratio per 100,000 live births. The measure of national income is GDP per capita; ${ }^{13}$ education 
is the percentage of the population age 15 or older who are illiterate; sanitation is the percentage of the population with access to improved sanitation facilities; and the measure for roads is paved roads (in kilometers) per unit area of country (in square kilometers). Data on government health expenditures are also in per capita terms and data for 2000 were obtained using the World Health Organization's World Health Report 2004.

Information on donor funding was obtained from the Creditor Reporting System table of the International Development Statistics online database. Funding commitments came from the Development Assistance Committee countries of the Organisation for Economic Co-operation and Development. These donations are bilateral and are usually used for specific off-budget health projects. Because bilateral donations are not counted as part of a country's government health budget, this variable was used as a measure of donor funding. However, this is the amount that the receiving countries were promised by donor countries in the given calendar year, not the actual amount received. The actual amount received is with a lag of a few years and may be different from the amount promised. For this reason the lagged value of the variable was used. For example, for the 2000 analysis the donor funding variable is per capita donor funding from Development Assistance Committee countries for health promised in 1998. For volatility, the standard deviation of the donor funding variable between 1994 and 1998 was used. Summary statistics of the log of these variables as used in the model are provided in table A5.1.

\section{Endogeneity and instruments}

Although many of the conditions of poverty-lack of clean water, sanitation, access to health services, and education-can lead to high levels of illness, micro theory suggests a reverse causality as well. Specifically, morbidity and ill health of the individuals in a family affects their ability to work and hence their income and can cause the household to fall into poverty. Similarly, it is possible that the government health expenditures variable may be correlated with the error term because governments may implicitly respond to poor health outcomes in prior years by adjusting health care spending in the current year. Here the source of endogeneity is not, per se, reverse causality-government budgets are set at the beginning of a year (with perhaps some deviations by the end of the year) while the health indicators are measured at the end of year-but rather due to omitted variables bias. Specifically, if current health outcomes are correlated with past health outcomes, and if the current government health expenditure is implicitly a function of prior health outcomes, equation (1) is misspecified to the extent that past health outcomes are not included in the equation.

To correct for potential endogeneity of income and government health expenditures, we estimate the models using instrumental variables techniques. The instrument that we use for national income is the consumption-investment ratio 
TABLE A5.1 Variable names and summary statistics

\begin{tabular}{|c|c|c|c|c|c|c|}
\hline Variable & Definition ( $N=113$ ) & Mean & Minimum $^{\mathrm{a}}$ & Maximum & $\begin{array}{l}\text { Standard } \\
\text { deviation }\end{array}$ & Median \\
\hline \multirow[t]{2}{*}{$\ln U 5 \mathrm{M}$} & In under-five mortality per & & & & & \\
\hline & 1,000 live births & 3.9892 & 1.3863 & 5.656 & 1.0009 & 3.912 \\
\hline \multirow[t]{2}{*}{ InMM } & In maternal mortality per 100,000 & & & & & \\
\hline & live births & 5.1603 & 0 & 7.6009 & 1.4905 & 5.0752 \\
\hline $\operatorname{lnGDP}$ & In GDP per capita ${ }^{b}$ & 8.0187 & 6.1527 & 10.2681 & 0.9317 & 8.1634 \\
\hline \multirow[t]{2}{*}{$\operatorname{lnGH}$} & In government health & & & & & \\
\hline & expenditures per capita ${ }^{b}$ & 4.2694 & 1.3863 & 7.688 & 1.2735 & 4.4188 \\
\hline \multirow[t]{2}{*}{$\ln E$} & In education (percent of & & & & & \\
\hline & $\begin{array}{l}\text { population age is or older } \\
\text { illiterate) }\end{array}$ & 2.4028 & -2.3026 & 4.4313 & 1.5535 & 2.7535 \\
\hline \multirow[t]{2}{*}{$\ln S$} & In sanitation (percent of & & & & & \\
\hline & $\begin{array}{l}\text { population with access to } \\
\text { improved sanitation) }\end{array}$ & 4.1493 & 2.0794 & 4.6052 & 0.5381 & 4.3567 \\
\hline \multirow[t]{2}{*}{$\ln R$} & In roads (paved roads per & & & & & \\
\hline & unit area) & 1.3805 & -8.8307 & 6.2198 & 2.3687 & 1.5023 \\
\hline \multirow[t]{2}{*}{$\operatorname{lnDF}$} & In donor funding per capita for & & & & & \\
\hline & basic health in $1998^{b}$ & -0.4775 & -8.3192 & 4.1263 & 2.702 & 0.2836 \\
\hline \multirow[t]{2}{*}{ Ivol } & In standard deviation of donor & & & & & \\
\hline & commitment from 1994 to 1998 & -0.0487 & -9.1084 & 3.3009 & 2.251 & 0.4741 \\
\hline $\operatorname{lnGH}{ }^{*} \mathrm{DF}$ & $(\operatorname{lnGH}-\overline{\operatorname{lnGH}}) \times(D F-\overline{D F})$ & -1.1532 & -34.0156 & 17.3859 & 5.2929 & -0.6972 \\
\hline
\end{tabular}

Source: Authors.

a. Log of zero was set equal to zero if the nonzero values were greater than one. However, if nonzero values were less than one, the log of zero was set equal to the log of the nonzero minimum value.

b. Converted to constant 2000 international dollars.

of the country because it is likely to be correlated with the GDP variable but not with under-five mortality or maternal mortality. Similarly, the instrument that we use for government health expenditures (and their interaction with donor funding) is military expenditures of neighboring countries (and their interaction with donor funding).

In addition to these variables, two other instruments were used. The World Bank staff annually assesses (and scores) the quality of polices and institutions in 4 broad areas with 20 criteria relevant to economic growth and poverty reduction of the countries borrowing from the International Bank for Reconstruction and Development and from the International Development Association. ${ }^{14}$ Of these 20 criteria, 4 score the countries on a scale of $1-5$ or $1-6$ on the following issues relating to economic management: management of inflation and currency accounting, fiscal policy, management of external debt, and management and sustainability of developmental programs. The average score on these four criteria was used as an additional instrument for GDP per capita. Similarly, scores on three additional criteria partly assess the policies for social inclusion and equity: gender equity, equity 
of public resource use, and policies for building human resources. The average score on these three criteria was used as an additional instrument for government health expenditures.

\section{Results}

For each of the two indicators (under-five mortality and maternal mortality), equation (1) was estimated under a set of alternative assumptions about the error term: (a) no correlation between any of the right-hand side variables and the error terms (no endogeneity), (b) the government health expenditures variable and its interaction with the donor funding variable are correlated with the error term but the income variable is not correlated with the error term (only $\ln G h$ and $\ln G h \times D F$ are endogenous), and (c) the income variable is also correlated with the error term $(\ln G h, \ln G h \times D F$ and $\ln I$ are all endogenous variables). Furthermore, for each of the three assumptions above, the equations were estimated with and without accounting for the presence of an unknown form of heteroscedasticity. Thus under assumption (a) we estimated ordinary least squares (OLS) estimates with the usual standard errors as well as the heteroscedastic ordinary least squares (HOLS). Similarly, under assumptions (b) and (c), standard two-stage least squares (2SLS) estimates as well as the Davidson and Mackinnon's general method of moments heteroscedastic two-stage least squares (GMM-H2SLS) estimator was used to compute the estimates and the standard errors. Graphical methods indicate that mild heteroscedasticity is present. More formal White tests based on the interaction of all terms yield chi-square statistics that are significant in the $\mathrm{p}=.10$ to $\mathrm{p}=.15$ range. Results for the two indicators (under-five mortality and maternal mortality) are summarized in table A5.2. The six columns in the table correspond to estimates based on assumptions (a), (b), and (c) with and without heteroscedasticity.

\section{Weak instruments, Hausman, and overidentification tests}

The reliability of the instrumental variables estimates (2SLS and GMM-H2SLS) relies on the use of good instruments. To establish the empirical relevance of these instruments, the weak instruments test was performed. In all "first-stage" regressions, the joint F-test for the additional instruments alone was almost always above the rule-of-thumb recommended value of 10 (test statistics are given near the bottom of table A5.2).

Additionally, the validity of the instruments (under heteroscedasticity) was tested through the usual overidentification tests. Thus for specification (VI) for under-five mortality and maternal mortality, the maintained null that the instruments are valid could not be rejected at the usual levels (for under-five mortality, the Hansen's J-statistic was 0.331, with a p-value of 0.954 , and for maternal mortality, the test statistic was 3.806 , with a p-value of 0.283 ). 
TABLE A5.2 Regression results

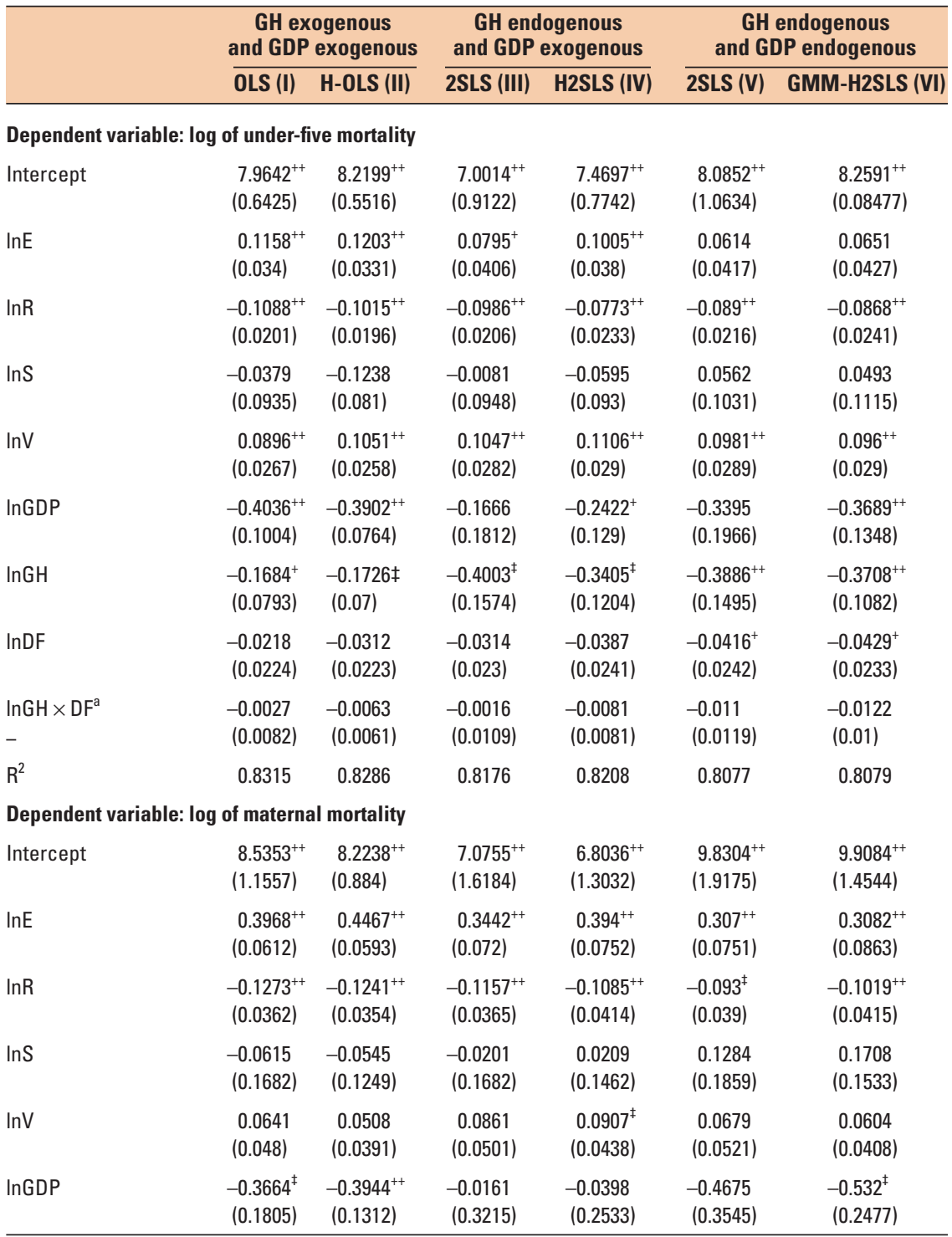


TABLE A5.2 Regression results (Continued)

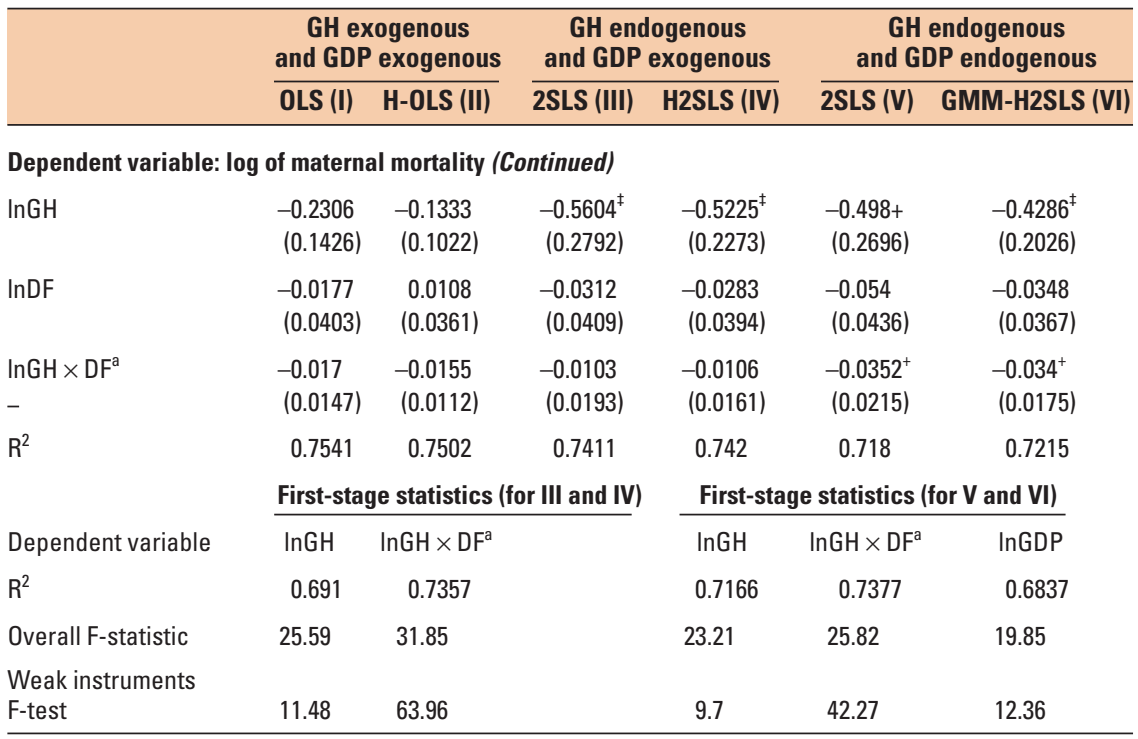

Source:

Note: Parameter standard errors are given in parenthesis.

a. The variable used in the regression was $(\operatorname{InGH}-\operatorname{Ln} \overline{G H}) *(D F-D \bar{F})$, where $\bar{x}$ stands for the mean value of the variable.

${ }^{++} \mathrm{p}$-value $=0.01$ or less; ${ }^{+} \mathrm{p}$-value $=0.05$ or less; ${ }^{\ddagger} \mathrm{p}$-value $=0.1$ or less

Finally, the Hausman statistic was employed to test for endogeneity of variables under assumptions (b) and (c) above. For 5 of 6 tests, the null hypothesis of no endogeneity was rejected. ${ }^{15}$ The Hausman test statistics (under heteroscedasticity) are summarized in table A5.3. The conclusions of the Hausman test results were identical when homoscedastic errors were assumed. (These gave six additional test statistics that are not given in table A5.3.) On the basis of the remaining five tests, Gh (and its interaction with $D F$ ) as well as the income variable are treated as endogenous variables.

TABLE A5.3 Hausman $X^{2}$-statistics (with heteroscedastic error terms)

\begin{tabular}{lcl}
\hline \multicolumn{1}{l}{ For under-five mortality equation } & \\
\hline II vs IV & 5.1709 & $\left(\operatorname{Pr} X^{2}(2) \geq 4.61\right) \leq 0.1$, hence can reject Null (at 10 percent) \\
II vs VI & 9.0995 & $\left(\operatorname{Pr}\left(X^{2}(3) \geq 7.81\right) \leq 0.05\right.$, hence can reject Null \\
IV vs VI & 16.05 & $\left(\operatorname{Pr}\left(X^{2}(1) \geq 3.84\right) \leq 0.05\right.$, hence can reject Null \\
\hline For maternal mortality equation & \\
\hline II vs IV & 4.2918 & $\left(\operatorname{Pr} X^{2}(2) \geq 4.61\right) \geq 0.1$, hence cannot reject Null \\
II vs VI & 12.9342 & $\left(\operatorname{Pr}\left(X^{2}(3) \geq 7.81\right) \leq 0.05\right.$, hence can reject Null \\
IV vs VI & 3.8282 & $\left(\operatorname{Pr}\left(X^{2}(1) \geq 2.71\right) \leq 0.1\right.$, hence can reject Null (at 10 percent) \\
\hline
\end{tabular}




\section{Elasticities}

Given the results of the test statistics above, we use the coefficients in the last column of table A5.2 as the "correct" coefficients.

The coefficients on the education and roads variables have the correct sign, but for under-five mortality the coefficient for education in specification (VI) is no longer statistically significant. A 10 percent reduction in illiteracy reduces underfive mortality by 0.65 percent and maternal mortality by 3.1 percent. Similarly, a 10 percent increase in the network of paved roads per unit area of the country reduces under-five mortality by about 0.87 percent and maternal mortality by about 1 percent. Note that the OLS coefficients biased these results away from zero, thus exaggerating their impact on these two Millennium Development Goal outcomes. Nonetheless, these are large effects. By contrast, the sign on the sanitation variable is expected to be negative and significant for both the indicators. However the coefficient is not significant in any of the estimations. A similar result (of nonsignificance) was observed elsewhere as well. Although it is certainly possible that sanitation, as defined here, has no impact on the health outcomes, this result is suspect. It is more likely that this variable is measured with error and hence the lack of significance may be due to attenuation bias.

Elasticity for per capita income is -0.3689 for under-five mortality and -0.532 for maternal mortality, and both are statistically significant at the 5 percent level.

The coefficient on $G$ is negative and significant for both under-five mortality and maternal mortality and increases in magnitude when the instrumental variable methods are used. The best point estimates of the coefficients on $G h$ are -0.37 for under-five mortality and -0.43 for maternal mortality. Due to the interaction with $D F$ the elasticity estimates range from -0.33 (country with lowest donor funding) to -0.55 (country with highest donor funding) with a mean value of -0.37 for underfive mortality. For maternal mortality the elasticity ranges from -0.31 (country with lowest donor funding) to -0.93 (again country with highest donor funding) with a mean value of -0.43 . Country-specific elasticities are give in table A5.4.

Elasticity for donor funding is negative and significant for under-five mortality but is not statistically significant for maternal mortality. This is likely because the off-budget bilateral funds are usually set aside for primary care, not secondary care projects.

Note that the elasticity of maternal mortality with respect to $G h$ is greater in magnitude than the elasticity of under-five mortality for countries that are above the mean value of donor funding. However, for countries that are at or below the mean value of donor funding the difference in the elasticity of maternal mortality and under-five mortality with respect to $G$ is very small (in some cases the elasticity of under-five mortality is larger than the elasticity of maternal mortality). The fact that elasticity for $G h$ increases in magnitude with donor funding is because of the negative sign on the interaction term between Gh and DF, which in the case of maternal mortality is also significant at the 5 percent level. 
TABLE A5.4 Elasticity of under-five mortality and maternal mortality for government health expenditures

\begin{tabular}{|c|c|c|c|c|c|c|c|c|}
\hline & $\begin{array}{l}\text { Under-five } \\
\text { mortality }\end{array}$ & $\begin{array}{l}\text { Standard } \\
\text { error }\end{array}$ & t-value & p-value & $\begin{array}{l}\text { Maternal } \\
\text { mortality }\end{array}$ & $\begin{array}{c}\text { Standard } \\
\text { error }\end{array}$ & t-value & p-value \\
\hline Albania & -0.414 & 0.1056 & -3.9224 & 0.0002 & -0.5494 & 0.1905 & -2.8845 & 0.0048 \\
\hline Algeria & -0.3308 & 0.1204 & -2.7483 & 0.0071 & -0.3171 & 0.2286 & -1.3869 & 0.1684 \\
\hline Argentina & -0.3305 & 0.1205 & -2.7427 & 0.0072 & -0.3162 & 0.2289 & -1.3814 & 0.1701 \\
\hline Armenia & -0.3765 & 0.1071 & -3.5142 & 0.0007 & -0.4447 & 0.1999 & -2.2247 & 0.0283 \\
\hline Azerbaijan & -0.3326 & 0.1196 & -2.78 & 0.0065 & -0.3221 & 0.2272 & -1.4178 & 0.1592 \\
\hline Bangladesh & -0.3373 & 0.1178 & -2.8617 & 0.0051 & -0.3351 & 0.2236 & -1.4986 & 0.137 \\
\hline Belarus & -0.3324 & 0.1197 & -2.7763 & 0.0065 & -0.3216 & 0.2274 & -1.4142 & 0.1603 \\
\hline Belize & -0.33 & 0.1207 & -2.734 & 0.0074 & -0.3148 & 0.2293 & -1.373 & 0.1727 \\
\hline Benin & -0.4387 & 0.1094 & -4.0103 & 0.0001 & -0.6182 & 0.1924 & -3.2128 & 0.0018 \\
\hline Bolivia & -0.421 & 0.1063 & -3.9623 & 0.0001 & -0.569 & 0.1904 & -2.9889 & 0.0035 \\
\hline Botswana & -0.3338 & 0.1192 & -2.8017 & 0.0061 & -0.3256 & 0.2262 & -1.4391 & 0.1531 \\
\hline Brazil & -0.3302 & 0.1206 & -2.7388 & 0.0073 & -0.3156 & 0.2291 & -1.3776 & 0.1713 \\
\hline Bulgaria & -0.3302 & 0.1206 & -2.7387 & 0.0073 & -0.3156 & 0.2291 & -1.3776 & 0.1713 \\
\hline Burkina Faso & -0.3513 & 0.1131 & -3.1073 & 0.0024 & -0.3744 & 0.2137 & -1.7518 & 0.0827 \\
\hline Burundi & -0.352 & 0.1129 & -3.1189 & 0.0023 & -0.3763 & 0.2133 & -1.7642 & 0.0806 \\
\hline Cambodia & -0.382 & 0.1063 & -3.5925 & 0.0005 & -0.4601 & 0.1976 & -2.3284 & 0.0218 \\
\hline Cameroon & -0.3537 & 0.1124 & -3.1473 & 0.0022 & -0.3809 & 0.2122 & -1.7948 & 0.0756 \\
\hline Cape Verde & -0.389 & 0.1056 & -3.6836 & 0.0004 & -0.4796 & 0.1952 & -2.4576 & 0.0156 \\
\hline Chad & -0.3805 & 0.1065 & -3.5709 & 0.0005 & -0.4558 & 0.1982 & -2.2992 & 0.0235 \\
\hline Chile & -0.3302 & 0.1206 & -2.7384 & 0.0073 & -0.3155 & 0.2291 & -1.3772 & 0.1714 \\
\hline China & -0.3306 & 0.1204 & -2.7457 & 0.0071 & -0.3167 & 0.2288 & -1.3844 & 0.1692 \\
\hline Colombia & -0.3309 & 0.1203 & -2.7494 & 0.007 & -0.3173 & 0.2286 & -1.3879 & 0.1681 \\
\hline Comoros & -0.4526 & 0.1131 & -4.0009 & 0.0001 & -0.6571 & 0.1963 & -3.3464 & 0.0011 \\
\hline Congo, Dem. Rep. & -0.3388 & 0.1173 & -2.8889 & 0.0047 & -0.3395 & 0.2225 & -1.5259 & 0.1301 \\
\hline Congo, Rep. & -0.3383 & 0.1175 & -2.88 & 0.0048 & -0.338 & 0.2229 & -1.5169 & 0.1323 \\
\hline Costa Rica & -0.332 & 0.1199 & -2.7693 & 0.0067 & -0.3204 & 0.2277 & -1.4073 & 0.1623 \\
\hline Côte d'Ivoire & -0.3773 & 0.107 & -3.5261 & 0.0006 & -0.447 & 0.1995 & -2.2401 & 0.0272 \\
\hline Croatia & -0.3318 & 0.1199 & -2.7665 & 0.0067 & -0.32 & 0.2278 & -1.4046 & 0.1631 \\
\hline Dominica & -0.4091 & 0.1052 & -3.8872 & 0.0002 & -0.5357 & 0.1909 & -2.8065 & 0.006 \\
\hline Dominican Republic & c -0.4485 & 0.1119 & -4.0075 & 0.0001 & -0.6456 & 0.195 & -3.3109 & 0.0013 \\
\hline Ecuador & -0.3402 & 0.1168 & -2.9133 & 0.0044 & -0.3433 & 0.2214 & -1.5504 & 0.1241 \\
\hline Egypt, Arab Rep. & -0.3361 & 0.1183 & -2.841 & 0.0054 & -0.3318 & 0.2245 & -1.478 & 0.1424 \\
\hline
\end{tabular}


TABLE A5.4 Elasticity of under-five mortality and maternal mortality for government health expenditures (continued)

\begin{tabular}{|c|c|c|c|c|c|c|c|c|}
\hline & $\begin{array}{l}\text { Under-five } \\
\text { mortality }\end{array}$ & $\begin{array}{c}\text { Standard } \\
\text { error }\end{array}$ & t-value & p-value & $\begin{array}{l}\text { Maternal } \\
\text { mortality }\end{array}$ & $\begin{array}{c}\text { Standard } \\
\text { error }\end{array}$ & t-value & p-value \\
\hline El Salvador & -0.3854 & 0.1059 & -3.6379 & 0.0004 & -0.4696 & 0.1964 & -2.3914 & 0.0186 \\
\hline Equatorial Guinea & -1.0837 & 0.5729 & -1.8915 & 0.0613 & -2.4185 & 0.9728 & -2.4861 & 0.0145 \\
\hline Eritrea & -0.3885 & 0.1057 & -3.6769 & 0.0004 & -0.4781 & 0.1953 & -2.4477 & 0.0161 \\
\hline Estonia & -0.3361 & 0.1183 & -2.8415 & 0.0054 & -0.3319 & 0.2245 & -1.4785 & 0.1423 \\
\hline Ethiopia & -0.3623 & 0.11 & -3.2927 & 0.0014 & -0.4051 & 0.207 & -1.9567 & 0.0531 \\
\hline Gabon & -0.3877 & 0.1057 & -3.6669 & 0.0004 & -0.4759 & 0.1956 & -2.4331 & 0.0167 \\
\hline Gambia, The & -0.3572 & 0.1114 & -3.2072 & 0.0018 & -0.3908 & 0.21 & -1.8604 & 0.0657 \\
\hline Georgia & -0.3547 & 0.1121 & -3.1648 & 0.002 & -0.3838 & 0.2116 & -1.8138 & 0.0726 \\
\hline Ghana & -0.425 & 0.1068 & -3.9795 & 0.0001 & -0.5801 & 0.1905 & -3.0444 & 0.003 \\
\hline Grenada & -0.3591 & 0.1109 & -3.2395 & 0.0016 & -0.3961 & 0.2089 & -1.8964 & 0.0607 \\
\hline Guatemala & -0.3961 & 0.1052 & -3.7657 & 0.0003 & -0.4993 & 0.1932 & -2.5849 & 0.0111 \\
\hline Guinea & -0.3803 & 0.1066 & -3.5688 & 0.0005 & -0.4554 & 0.1983 & -2.2964 & 0.0237 \\
\hline Guinea-Bissau & -0.5249 & 0.1462 & -3.5905 & 0.0005 & -0.8589 & 0.2436 & -3.5263 & 0.0006 \\
\hline Guyana & -0.33 & 0.1207 & -2.734 & 0.0074 & -0.3148 & 0.2293 & -1.373 & 0.1727 \\
\hline Haiti & -0.4115 & 0.1054 & -3.9053 & 0.0002 & -0.5425 & 0.1907 & -2.8453 & 0.0053 \\
\hline Honduras & -0.3703 & 0.1083 & -3.4206 & 0.0009 & -0.4274 & 0.2028 & -2.1076 & 0.0375 \\
\hline Hungary & -0.3329 & 0.1195 & -2.7857 & 0.0063 & -0.3231 & 0.227 & -1.4234 & 0.1576 \\
\hline Iceland & -0.33 & 0.1207 & -2.734 & 0.0074 & -0.3148 & 0.2293 & -1.373 & 0.1727 \\
\hline India & -0.3352 & 0.1186 & -2.8262 & 0.0056 & -0.3295 & 0.2252 & -1.4633 & 0.1464 \\
\hline Indonesia & -0.3386 & 0.1174 & -2.885 & 0.0048 & -0.3388 & 0.2226 & -1.5219 & 0.1311 \\
\hline Jamaica & -0.3317 & 0.12 & -2.7636 & 0.0068 & -0.3195 & 0.2279 & -1.4018 & 0.1639 \\
\hline Jordan & -0.4269 & 0.1071 & -3.9862 & 0.0001 & -0.5853 & 0.1907 & -3.0695 & 0.0027 \\
\hline Kazakhstan & -0.383 & 0.1062 & -3.6058 & 0.0005 & -0.4629 & 0.1972 & -2.3466 & 0.0208 \\
\hline Kenya & -0.3684 & 0.1087 & -3.3902 & 0.001 & -0.422 & 0.2038 & -2.0709 & 0.0408 \\
\hline Korea, Rep. & -0.33 & 0.1207 & -2.734 & 0.0074 & -0.3148 & 0.2293 & -1.373 & 0.1727 \\
\hline Kyrgyz Republic & -0.4729 & 0.1203 & -3.9295 & 0.0002 & -0.7137 & 0.2054 & -3.4739 & 0.0007 \\
\hline Lebanon & -0.3372 & 0.1179 & -2.8602 & 0.0051 & -0.3349 & 0.2237 & -1.4971 & 0.1374 \\
\hline Lesotho & -0.33 & 0.1207 & -2.734 & 0.0074 & -0.3148 & 0.2293 & -1.373 & 0.1727 \\
\hline Lithuania & -0.3308 & 0.1204 & -2.7487 & 0.0071 & -0.3172 & 0.2286 & -1.3873 & 0.1683 \\
\hline Macedonia, FYR & -0.4836 & 0.1249 & -3.8722 & 0.0002 & -0.7435 & 0.2117 & -3.5123 & 0.0007 \\
\hline Madagascar & -0.3574 & 0.1113 & -3.2105 & 0.0018 & -0.3913 & 0.2099 & -1.864 & 0.0651 \\
\hline Malawi & -0.3748 & 0.1074 & -3.4892 & 0.0007 & -0.44 & 0.2006 & -2.1928 & 0.0306 \\
\hline
\end{tabular}


TABLE A5.4 Elasticity of under-five mortality and maternal mortality for government health expenditures (continued)

\begin{tabular}{|c|c|c|c|c|c|c|c|c|}
\hline & $\begin{array}{l}\text { Under-five } \\
\text { mortality }\end{array}$ & $\begin{array}{c}\text { Standard } \\
\text { error }\end{array}$ & t-value & $p$-value & $\begin{array}{l}\text { Maternal } \\
\text { mortality }\end{array}$ & $\begin{array}{c}\text { Standard } \\
\text { error }\end{array}$ & t-value & p-value \\
\hline Malaysia & -0.33 & 0.1207 & -2.7343 & 0.0074 & -0.3149 & 0.2293 & -1.3732 & 0.1726 \\
\hline Mali & -0.3402 & 0.1168 & -2.9137 & 0.0044 & -0.3434 & 0.2214 & -1.5507 & 0.124 \\
\hline Mauritania & -0.4167 & 0.1058 & -3.9388 & 0.0001 & -0.5568 & 0.1904 & -2.9246 & 0.0042 \\
\hline Mauritius & -0.3331 & 0.1195 & -2.7881 & 0.0063 & -0.3234 & 0.2268 & -1.4257 & 0.1569 \\
\hline Mexico & -0.3301 & 0.1206 & -2.736 & 0.0073 & -0.3151 & 0.2292 & -1.3749 & 0.1721 \\
\hline Moldova & -0.3457 & 0.1149 & -3.0096 & 0.0033 & -0.3587 & 0.2175 & -1.6489 & 0.1022 \\
\hline Mongolia & -0.3722 & 0.1079 & -3.4497 & 0.0008 & -0.4327 & 0.2019 & -2.1434 & 0.0344 \\
\hline Morocco & -0.3354 & 0.1185 & -2.8295 & 0.0056 & -0.33 & 0.225 & -1.4666 & 0.1455 \\
\hline Mozambique & -0.3914 & 0.1054 & -3.7129 & 0.0003 & -0.4864 & 0.1944 & -2.5016 & 0.0139 \\
\hline Namibia & -0.5531 & 0.1632 & -3.3882 & 0.001 & -0.9376 & 0.2707 & -3.464 & 0.0008 \\
\hline Nepal & -0.3384 & 0.1174 & -2.8826 & 0.0048 & -0.3385 & 0.2227 & -1.5195 & 0.1317 \\
\hline Nicaragua & -0.3776 & 0.107 & -3.5305 & 0.0006 & -0.4478 & 0.1994 & -2.2458 & 0.0268 \\
\hline Niger & -0.3569 & 0.1114 & -3.2031 & 0.0018 & -0.3901 & 0.2102 & -1.8559 & 0.0663 \\
\hline Nigeria & -0.3306 & 0.1204 & -2.7449 & 0.0071 & -0.3165 & 0.2288 & -1.3835 & 0.1695 \\
\hline Pakistan & -0.3325 & 0.1197 & -2.7785 & 0.0065 & -0.3219 & 0.2273 & -1.4164 & 0.1597 \\
\hline Panama & -0.3322 & 0.1198 & -2.7733 & 0.0066 & -0.3211 & 0.2275 & -1.4112 & 0.1612 \\
\hline Paraguay & -0.4544 & 0.1137 & -3.9971 & 0.0001 & -0.662 & 0.197 & -3.3608 & 0.0011 \\
\hline Peru & -0.3701 & 0.1083 & -3.418 & 0.0009 & -0.4269 & 0.2029 & -2.1044 & 0.0378 \\
\hline Philippines & -0.3519 & 0.1129 & -3.118 & 0.0024 & -0.3761 & 0.2133 & -1.7632 & 0.0808 \\
\hline Romania & -0.3316 & 0.12 & -2.7625 & 0.0068 & -0.3194 & 0.228 & -1.4008 & 0.1643 \\
\hline Russian Federation & -0.3354 & 0.1186 & -2.8283 & 0.0056 & -0.3298 & 0.2251 & -1.4654 & 0.1458 \\
\hline Rwanda & -0.452 & 0.1129 & -4.002 & 0.0001 & -0.6555 & 0.1961 & -3.3417 & 0.0012 \\
\hline Senegal & -0.4533 & 0.1133 & -3.9995 & 0.0001 & -0.659 & 0.1966 & -3.3519 & 0.0011 \\
\hline Sierra Leone & -0.361 & 0.1104 & -3.2706 & 0.0015 & -0.4013 & 0.2078 & -1.9315 & 0.0561 \\
\hline Singapore & -0.3301 & 0.1206 & -2.7365 & 0.0073 & -0.3152 & 0.2292 & -1.3755 & 0.1719 \\
\hline South Africa & -0.3465 & 0.1146 & -3.0229 & 0.0032 & -0.3608 & 0.217 & -1.6628 & 0.0994 \\
\hline Sri Lanka & -0.3341 & 0.1191 & -2.8064 & 0.006 & -0.3263 & 0.226 & -1.4437 & 0.1518 \\
\hline St. Kitts and Nevis & -0.3521 & 0.1128 & -3.1206 & 0.0023 & -0.3766 & 0.2132 & -1.766 & 0.0803 \\
\hline St. Lucia & -0.3616 & 0.1102 & -3.2816 & 0.0014 & -0.4032 & 0.2074 & -1.944 & 0.0546 \\
\hline $\begin{array}{l}\text { St. Vincent and } \\
\text { the Grenadines }\end{array}$ & -0.3365 & 0.1181 & -2.8479 & 0.0053 & -0.3329 & 0.2242 & -1.4848 & 0.1406 \\
\hline Sudan & -0.3461 & 0.1147 & -3.0172 & 0.0032 & -0.3599 & 0.2172 & -1.6569 & 0.1006 \\
\hline
\end{tabular}


TABLE A5.4 Elasticity of under-five mortality and maternal mortality for government health expenditures (continued)

\begin{tabular}{lllllllll}
\hline & $\begin{array}{c}\text { Under-five } \\
\text { mortality }\end{array}$ & $\begin{array}{c}\text { Standard } \\
\text { error }\end{array}$ & t-value & p-value & $\begin{array}{c}\text { Maternal } \\
\text { mortality }\end{array}$ & $\begin{array}{c}\text { Standard } \\
\text { error }\end{array}$ & t-value & p-value \\
\hline Swaziland & -0.33 & 0.1207 & -2.7347 & 0.0073 & -0.3149 & 0.2293 & -1.3736 & 0.1725 \\
Tajikistan & -0.3406 & 0.1166 & -2.9206 & 0.0043 & -0.3445 & 0.2211 & -1.5577 & 0.1223 \\
Tanzania & -0.3675 & 0.1088 & -3.3771 & 0.001 & -0.4197 & 0.2042 & -2.0552 & 0.0424 \\
Thailand & -0.3302 & 0.1206 & -2.7375 & 0.0073 & -0.3154 & 0.2291 & -1.3764 & 0.1717 \\
Togo & -0.3835 & 0.1062 & -3.6123 & 0.0005 & -0.4642 & 0.1971 & -2.3556 & 0.0204 \\
Trinidad and Tobago & -0.33 & 0.1207 & -2.7347 & 0.0073 & -0.3149 & 0.2293 & -1.3737 & 0.1725 \\
Tunisia & -0.3333 & 0.1194 & -2.7919 & 0.0062 & -0.324 & 0.2267 & -1.4295 & 0.1558 \\
Turkey & -0.3301 & 0.1206 & -2.7364 & 0.0073 & -0.3152 & 0.2292 & -1.3753 & 0.172 \\
Turkmenistan & -0.3412 & 0.1164 & -2.9318 & 0.0041 & -0.3463 & 0.2207 & -1.5691 & 0.1197 \\
Uganda & -0.4131 & 0.1055 & -3.9163 & 0.0002 & -0.5469 & 0.1905 & -2.8702 & 0.005 \\
Ukraine & -0.3438 & 0.1155 & -2.9774 & 0.0036 & -0.3535 & 0.2188 & -1.6157 & 0.1092 \\
Uruguay & -0.3319 & 0.1199 & -2.7671 & 0.0067 & -0.3201 & 0.2278 & -1.4052 & 0.1629 \\
Uzbekistan & -0.3438 & 0.1155 & -2.9772 & 0.0036 & -0.3535 & 0.2188 & -1.6155 & 0.1092 \\
Venezuela, RB & -0.3302 & 0.1206 & -2.7386 & 0.0073 & -0.3156 & 0.2291 & -1.3775 & 0.1713 \\
Vietnam & -0.3735 & 0.1077 & -3.4692 & 0.0008 & -0.4363 & 0.2013 & -2.1676 & 0.0325 \\
Yemen, Rep. & -0.3325 & 0.1197 & -2.7776 & 0.0065 & -0.3218 & 0.2273 & -1.4155 & 0.1599 \\
Zambia & -0.3506 & 0.1133 & -3.0949 & 0.0025 & -0.3724 & 0.2142 & -1.7386 & 0.0851 \\
Zimbabwe & -0.3979 & 0.1051 & -3.7849 & 0.0003 & -0.5044 & 0.1928 & -2.6167 & 0.0102 \\
\hline
\end{tabular}

That donor funding marginally increases the elasticity of maternal mortality with respect to government expenditures but not of under-five mortality is puzzling, especially because donor funding does not seem to have any direct impact on maternal mortality.

\section{Endnotes}

1. Asymmetry in budgeting refers to the difficulties that governments face in cutting expenditures when resources are declining.

2. A model developed for this book makes several adjustments to the Filmer-Pritchett and Wagstaff-Claeson models. Annex 5.1 provides a detailed technical explanation of the model. The model makes four econometric adjustments. First, both government health expenditures and income are treated as endogenous variables. This allows for a circular relationship between heath outcomes and income (heath outcomes may improve as income increases, but improved outcomes may also lead to increased income) and between government health expenditures and outcomes (for example, larger expenditures may lead 
to improved outcomes, but the government may increase expenditures when outcomes are poor). Second, donor funding variables are lagged to account for the fact that commitments are disbursed at a later date but also solve endogeneity of donor funding. Third, endogeneity and choice of instruments were tested using Staiger and Stock (1997) weak instrument tests and Hausman (1978) tests. Fourth, the presence of heteroscedasticity was tested for and corrected (using a general method of moments heteroscedastic two-stage least squares estimator).

3. As in other studies (Filmer and Pritchett 1999; Wagstaff 2002b; Wagstaff and Claeson 2004), the model did not include private expenditures as part of the explanatory variables. Filmer and Pritchett (1999) explained that their main reason for not estimating health status as a function of private expenditures on health is that private expenditures are influenced rather than determined by policy. Economic agents spend out of pocket when a health event has taken place; thus, health expenditures and the dependent variables are endogenous and very hard to separate. In any event, the absence of private health expenditures as an explanatory variable could lead to omitted variable bias. Therefore, private expenditures were included in the model and shown not to be statistically significant. Their inclusion did not generate a significant change in other coefficients. Therefore, private expenditures were dropped from the model for comparative purposes with other models.

4. There are two related issues with the donor funding variable. First is the double counting of donor funding. Grants and loans provided by various donor agencies (such as the World Bank and the United Nations) are given directly to the government for health and other purposes, and hence are already counted in the government health expenditures variable. Information on donor funding that is actually available to various countries from all sources and that is reported "on budget" is not readily available. Information was used from the OECD/DAC for specific health projects that are off-budget. But this measure raises a second issue: the variable captures the amount of the donation receiving countries were promised by the DAC countries in the given calendar year, not the actual amount received in donations. The amount received can lag by a few years and even then may differ from the amount promised. For this reason, the lagged value of the variable was used. For example, for the analysis for 2000, the donor funding variable is per capita donor funding from DAC countries for health promised in 1998 (in 2000 Int\$).

5. A small change in government health expenditures $(G h)$ will be associated with a direct effect and an indirect effect. The direct effect is the marginal impact that a change in government expenditures may have on under-five mortality or maternal mortality. However, governments may use their resources to influence other Millennium Development Goal indicators, such as nutrition, which may have an impact on under-five mortality; this is the indirect effect. Put another way, the coefficient on Gh represents the percentage change in the indicators under-five mortality or maternal mortality ratio associated with a 1 percent change in $G$, holding income $(I)$, education $(E)$, roads $(R)$, sanitation $(S)$, and donor funding $(D F)$ constant but not the other Millennium Development Goal indicators. The coefficients in the table, therefore, provide the net impact of changes in the independent variables on the under-five mortality rate and maternal mortality ratio. For ease of exposition, this net impact of changes is called the net elasticity impact or just elasticity.

6 . The under-five mortality rate is measured as deaths of children under the age of five years per 1,000 live births. The maternal mortality ratio is measured as a ratio of maternal deaths per 100,000 live births. The measure of income is GDP per capita in constant 2000 
international dollars, education is the percentage of the population age 15 or older who are illiterate, sanitation is the percentage of the population with access to improved sanitation facilities, and roads are measured as paved roads (in kilometers) per unit area of country (in square kilometers). Donor funding refers to commitments made by donors with a twoyear lag to finance health activities outside the government's budget. Volatility is the standard deviation of the per capita donor commitments from 1994 to 1998.

7. All currency measurements were converted to constant 2000 international dollars.

8 . The results are robust to other measures of volatility of donor funding.

9. The coefficients in the table are not elasticities in the strict economic sense, but rather some sort of "net elasticities." It is not possible to separate the direct and indirect effects because the direct partial elasticity coefficients are not identified in the estimation model used. Thus, whenever the term "elasticity" of an outcome indicator with respect to a covariate is used, it refers to the net elasticity. Also, to estimate the elasticity of government health expenditures on under-five mortality and maternal mortality, the impact of donor funding on government health expenditures must also be taken into account (the interaction term). Thus, to estimate the impact of government health expenditures on under-five mortality or maternal mortality, some aggregation of coefficients is necessary. The interpretation of the government health expenditures coefficients in the table as elasticities is still correct for the average elasticity across countries (see annex 5.1 for details). Wagstaff and Claeson (2004) reported the elasticity for under-five mortality with respect to per capita income in the range of -0.3 percent to -0.5 percent, while Filmer and Pritchett (1999) had an estimate of -0.6 percent. Their studies treated Gh as endogenous but not GDP. The estimates across countries are presented in annex 5.1.

From an econometric perspective the $S$ variable (sanitation) appears to be measured with error and hence the lack of significance may be due to attenuation bias rather than anything else. Two options for checking this hypothesis are to use a different measure of this variable (preferably from some other source) or to find some instruments for this variable. Currently, the data available fall short on both accounts, and so link between the lack of significance and attenuation bias was not tested.

10. The analysis and results are similar to Wagstaff and Claeson (2004) and figures 5.1 and 5.2 mirror their analysis. Differences arise largely as a result of the significant coefficient of the impact of government health expenditures on outcomes in the model here and the presence of donor funding.

11. The average rate of decline needed between 1990 and 2015 to reach the under-five mortality goal across all regions is 4.2 percent. However, given the slow progress from 1990 to 2000 , the rate of decline needs to be larger from 2000 to 2015 and larger in some regions than in others.

12. This annex is based on the working paper "Government Health Expenditures, Donor Funding, and Health Outcomes" (2005) by Bokhari, Gottret, and Gai. For a copy of the working paper send an email to fbokhari@fsu.edu.

13. All currency measurements were converted to constant 2000 international dollars.

14. The four broad areas are economic management, structural policies, policies for social inclusion and equity, and public sector management.

15. There are three such tests for each indicator equation. Thus, the test statistics can be constructed by comparing: (1) coefficients under assumption (a) where no variable is exogenous to those under (b) where only government health expenditures (and their interaction) 
are endogenous; (2) coefficients under assumption (a) where no variable is exogenous to those under (c) where income and government health expenditures (and their interaction) are endogenous; and (3) coefficients under assumption (b) where only government health expenditures (and their interaction) are endogenous to those under (c) where income and government health expenditures (and their interaction) are endogenous. Note that the third test statistic is an incremental test. It tests whether, given that government health expenditures (and their interaction with $D F$ ) are endogenous, income is endogenous.

\section{References}

Filmer, D., and L. Pritchett. 1999. “The Impact of Public Spending on Health: Does Money Matter?" Social Science and Medicine 49 (10): 1309-23.

Hausman, J. A. 1978. “Specification Tests in Econometrics.” Econometrica 46 (6): 1251-71.

Herrera, S., and G. Pan. 2005. "Efficiency of Public Spending in Developing Countries: An Efficiency Frontier Approach.” World Bank, Washington, D.C.

Leipziger, D., M. Fay, Q. Wodon, and T. Yepes. 2003. "Achieving the Millennium Development Goals: The Role of Infrastructure.” World Bank, Washington, D.C.

Musgrove, P. 1996. "Public and Private Roles in Health.” Technical Report 339, World Bank, Washington, D.C.

Paternostro, S., A. Rajaram, and E. Tiongson. 2004. "How Does the Composition of Public Spending Matter?” World Bank, Washington, D.C.

Wagstaff, A. 2002a. "Heath Spending and Aid as Escape Routes from the Vicious Circle of Poverty and Health." Paper prepared for British Association for the Advancement of Science Festival of Science, Leicester, U.K., September 12.

. 2002b. "Intersectoral Synergies and the Health MDGs: Preliminary Cross-Country Findings, Corroboration, and Policy Simulations." Paper prepared for the Development Committee on Accelerating Progress toward the HNP MDGs, Washington, D.C., December 6.

Wagstaff, A., and M. Claeson. 2004. The Millennium Development Goals for Health: Rising to the Challenges. Washington, D.C.: World Bank. 
